\title{
A Review of the Syntactic Priming-A Research Method in Sentence Production
}

\author{
Hao Feng, Luyao Chen, Lijuan Feng, Liping Feng \\ College of Chinese Language and Culture, Beijing Normal University, Beijing, China \\ Email: blcurex@gmail.com, harrychenlyzml@gmail.com, Ifeng@mail.bnu.edu.cn, fengliping@bnu.edu.cn
}

Received 17 September 2014; revised 3 November 2014; accepted 17 November 2014

Copyright (C) 2014 by authors and Scientific Research Publishing Inc.

This work is licensed under the Creative Commons Attribution International License (CC BY). http://creativecommons.org/licenses/by/4.0/

(c) (i) Open Access

\begin{abstract}
The syntactic priming is not only a very important repetitive priming phenomenon, it is also important for studying the syntactic representation and the speech production mechanism. Since the priming is related to the selecting process of the target sentences, it is of serious requirement for both the experimental materials and paradigms. The main questions studied in the syntactic priming correlates with the construction, the syntactic hierarchy and the representation of verbs, etc. Mastering the syntactic priming's experimental paradigm and knowing the corresponding research questions would be of great significance to studying the syntactic representation and the syntactic teaching in the field of teaching Chinese as a second language.
\end{abstract}

\section{Keywords}

\section{Sentence Production, Syntactic Priming, Syntactic Representation}

\section{Introduction}

We always repeat other's speech. When you read this article, you have repeated the words I have written. Does this phenomenon have a name? The syntactic priming denotes to the phenomenon that people tend to repeat their syntactic structures used before during monologues or conversations. For instance, Weiner \& Labov (1983) found that when the audiences heard one passive sentence among five sentences, he would then produce a sentence same in the passive voice. If not differentiated rigidly, the syntactic priming can also be called the structural priming. Some researchers deem that the syntactic priming contains the lexical boost effect, while the structural priming may only have the abstract language structure's priming (Pickering \& Ferreira, 2008), which will not be distinguished by this article. The syntactic priming exists in the processes of both speech production and comprehension (Bock, Dell, Chang, \& Onishi, 2007), and this paper will mainly study the syntactic priming's experimental paradigms related to speech production. 
The syntactic priming is not only a phenomenon, but also a very effective experimental method for investigating the syntactic representation (Bock, 1986; Pickering \& Ferreira, 2008). Some questions it studied are listed below.

(1) Which is the syntactic representation, the abstract syntactic form or the construction?

(2) The psychological reality of the syntactic processing in a hierarchical and/or linear way.

(3) Speech production mechanisms.

(4) The cerebral activity during the speech production.

Similar to the lexical priming, the basic experimental paradigm is to change the priming sentences' types, controlling the relationship (structural, semantic and lexical etc.) between the priming sentences and the target sentences, so as to explore the correlative questions of the syntactic priming. Meanwhile, the priming touches upon the selecting process of the subject's priming sentence production, so there are some requirements on the priming sentences in the experiment; on the other hand, since related to the study of speech production, there are also some requirements on the experimental techniques.

Next we will comprehensively study the syntactic priming of the speech production in terms of the related syntactic structures, the experimental paradigms, the main questions, and the mechanisms.

\section{The Syntactic Structures Related to the Syntactic Priming}

Bock (1986) is the first person who uses the experimental paradigm to study the syntactic priming phenomenon of the speech production. The priming sentences have two types: (1) The prepositonal-object dative sentence, such as "a rock star sold some cocaine to an undercover agent." (2) The double-object dative sentence, like” a rock star sold an undercover agent some cocaine”. The target pictures can be produced by either the prepositional-object dative sentences or the double-object dative sentences. The result showed that the prepositonal-object dative sentences could promote the production of the sentences in the same form, so could the double-object dative sentences. There are two kinds of prepositions ("to" and “for") in the prepositional-object dative sentences, and the result showed little difference between the priming effects from the two different prepositions, indicating that the function words' repetition could not result in the priming.

After this work, many researchers have adopted the prepositonal-object and double-object structures to study the syntactic priming in a native language research (Bock, 1989; Bock \& Loebell, 1990; Cleland \& Pickering, 2006; Corley \& Scheepers, 2002; Hare \& Goldberg, 1999; Pickering \& Branigan, 1998). Most researches of bilingualism also adopt these two syntactic structures to explore the bilingual syntactic priming effect (Loebell \& Bock, 2003; McDonough, 2006; Schoonbaert, Hartsuiker, \& Pickering, 2007). Researches studying the syntactic priming of learning English as a second language in China mainly use these two kinds of syntactic structures as well (Jiang, 2009).

The active sentence ("one of the fans punched the referee") and the passive sentence ("the referee was punched by one of the fans”) are experimental materials for studying the syntactic priming also, but the agent's animacy and the positions of the agent and the patient in the target picture may influence the passive sentence's priming effect (Bock, 1986). Zhang \& Lu (2012) studied the syntactic priming effect of the passive sentence's production by the Chinese-English bilinguals, they found that when the priming sentences were concrete, the marked passive sentences could boot more passive sentences than the unmarked ones; when the priming sentences were abstract, the difference between the passive sentences' priming effects was not significant no matter whether the passive sentence was marked or unmarked. This illustrates that both the sentence's concreteness and the passive sentence's markedness are important factors for impacting upon the passive sentence's syntactic priming.

The researches, taking Chinese as a second language, likewise adopt the active and the passive sentences as the experimental materials. Cao \& Mou (2013) studied the “BA (“把” in Chinese)” sentence’s and “BEI (“被” in Chinese)" sentence's syntactic priming phenomena. The result reflected that the "BA" sentence had a greater priming effect than the "BEI" sentence, and the repeated verbs in priming sentences and target sentences could enhance the priming effect. Zha \& Wu (2014) investigated the syntactic priming effects between the Chinese native speakers and the high-level Chinese learners. According to the result, it can be found that the learners' active sentence priming effect was stronger than the native speakers, but the "BA" sentence's priming effect was

\footnotetext{
${ }^{*}$ This article has received supports from the key project of the National Social Science Fund (NO. 12AZD113) and the general project of the National Social Science Fund (NO. 14BYY146).
} 
weaker than the native speakers, and the two groups of passive sentence's priming effect had no significant difference. It is noteworthy that in this experiment, the two groups' unequal sample size and the "BA" sentence's difficulty may affect the experiment's result.

There are other structures for inspecting the speech production's syntactic priming, such as the interchangeable sentences which indicate directions like" the ball is on the table" and "on the table is a ball" (Hartsuiker, Kolk, \& Huiskamp, 1999); the interchangeable past particles and the auxiliaries at the end of the clause in Dutch (Hartsuiker \& Westenberg, 2000); the complex noun forms like "the red sheep" and "the sheep that is red" (Cleland \& Pickering, 2003); the German relative clauses (Scheepers, 2003); "that" (in different syntactic positions having different meanings) (Ferreira, 2003); synonymous Chinese idioms like “鸡飞蛋打 (ji-fei-dan-da, hen-has flown-eggs-are broken, the hen has flown away and the eggs in the coop are broken—all is lost)" and “人财两空 (ren-cai-liang-kong, men-money-two-lost, lose both men and money)” (Zhang, 2012).

Generally speaking, since the priming is correlative with the selecting process of the target sentence, the syntactic priming target sentence utilized into the experiment should satisfy a condition-interchangeability. That is to say, target sentences should be two sentences which are different in syntactic structures but similar in meanings.

The studies about Chinese as a second language should also abide by the principle of the target sentences' interchangeability, but whether "BA" sentence and "BEI" sentence, or "BEI" sentence and the active sentence can be viewed as target sentences that are semantically synonymous is still questionable. Moreover, whether the meaning of disposition of "BA" sentence and the meaning of impairment of "BEI" sentence will influence subjects' selections towards the target structures, and in the meantime whether the syntactic priming is affected by semantic priming or not still urge the researchers to have a good consideration. At present, appropriate materials for studying syntactic priming in Chinese include the sentences containing both the quasi bivalent verb and the pre-prepositional frame coordination structure (or the post-prepositional frame coordination structure) (here means the structures in which the frame prepositional phrases located before or after the verbs), for example, “政府服务于百姓 (zhengfu-fuwu-yu-baixing, the government-serves-for-the people, the government serves for the people)” and “政府给百姓服务 (zhengfu-gei-baixing-fuwu, the government-for-people-serve, the government serves for the people)" (Yang \& Shi, 2013). These two structures' differences of styles and frequencies of use would not impact the syntactic priming qualitatively (Segaert, Menenti, Weber, \& Hagoort, 2011).

\section{The Syntactic Priming's Study Paradigms}

The syntactic priming's study paradigms in the researches of the speech production mainly include: the picture depiction paradigm (Bock, 1986), the instantaneous sentence-recall paradigm (Potter \& Lombardi, 1998), and the written/spoken sentence completion paradigm (Pickering \& Branigan, 1998; Hartsuiker \& Westenberg, 2000), etc.

\subsection{The Picture Depiction Paradigm}

Bock (1986) used three syntactic priming experiments to study the syntactic structure's function in the speech production. The experimental materials consist of the priming sentences, the filler sentences, the pictures for producing target sentences and filler sentences. The experiments require the subjects to learn the filler sentences and filler pictures. The task demands subjects to judge whether the sentence (including both the priming sentences and the filler sentences) played by the recorder have been learned before, and to repeat it loudly, and then to judge whether the picture displayed have been seen before and to describe the event depicted in the picture by one sentence. The aim of the experiment is to inspect the structures' influence of the repeated priming sentences upon the syntactic structures of target sentences produced by the target pictures. The result manifested that no matter what the structure is (active/passive, or prepositonal-object dative/double-object), all the priming sentences can start the syntactic structures’ priming. Bock \& Loebell (1990) adopted the picture depiction paradigm to prove that this kind of priming effect could not be attributed to the word repetition, same thematic roles or the same rhythms.

Branigan, Pickering \& Cleland (2000) studied the syntactic priming in the conversation. They believed that Bock's experiments should be tested in the real interlocutory environment. The experiment used the confederate scripting technology to describe the pictures. In the experiment, there is a true subject and a fake one (experimenter), but the true subject knows nothing about this. The researchers told the subjects that the aim of the 
experiment is to study how people communicate with each other when they can not see their partner's face respectively. During the experiment, the two subjects take turns to describe the picture, and the confederate reads the script prepared in advance. The true subject should find out the picture described by the confederate and describe the target picture, then the confederate need find out the target picture.

Hartsuiker, Pickering \& Veltkamp (2004) applied the confederate scripting technology into the study of the cross-linguistic syntactic priming between Spanish and English. The experimental procedures are similar to the native language study, but the true subject describe the target picture in English while the confederate uses Spanish, which actually ensured that during the process of depicting the target picture, the confederates presented Spanish priming sentences, whereas the true subjects have produced English target sentences.

Studies of the syntactic priming in China mostly employ the picture depiction paradigm. Jiang (2009) explored the semantic priming of the Chinese-English bilinguals' double-object and prepositional-object structures, and the author thought that the priming process was the result from the combined action of both structure and meaning. Zhang \& Wang (2012) used the picture depiction paradigm to study the cross-linguistic priming phenomenon of Indonesian learners' Chinese sentence production in different language proficiency.

On account of the concreteness of the pictures' contents, the meanings of the target sentences in the picture depiction paradigm are generally concrete. Thus, to study the sentence's syntactic priming effect which expresses an abstract meaning entails a better research method.

\subsection{The Instantaneous Sentence-Recall Paradigm}

Potter \& Lombardi (1998) adopted the instantaneous sentence-recall paradigm to study the syntactic priming effect. The experiment presented the target sentences through the rapid serial visual presentation (RSVP) method: first, the target sentence which expresses the dative structure was presented rapidly in a word for the unit, every word was presented for $100 \mathrm{~ms}$; then, the subject read the priming sentence, recalled it then recall the target sentence whose meaning can be expressed by two different syntactic structures. This research revealed that even though different from the structure of target sentence, the structure of priming sentence would affect the selection of the structure of target sentence in a significant way.

In accordance with the characteristics in Chinese, Zhang (2012) improved the instantaneous sentence-recall paradigm to explore the syntactic priming phenomenon in the Chinese four-character structure idiom production. Since Chinese has few idioms that, except for the different syntactic structures, have the same meanings and morphemes, they could not completely repeat the experimental paradigm utilized in Potter \& Lombardi (1998). However, there are a good many synonymous idioms like “鸡飞蛋打” and “人财两空” whose syntactic structures differ from each other (“鸡飞蛋打” is a coordinative idiom, while “人财两空” is a subject-predicate idiom). A subject firstly should read the target idiom's meaning (such as, all is lost), and then read the priming idiom (such as “风驰电掣 (feng-chi-dian-che, wind-run quickly-flash-strike, swift as the wind and quick as lightning)”. The priming idiom's meaning has no relationship with the two synonymous target idioms, but the priming idiom's structure is identical to one of the target idioms' (for instance, “鸡飞蛋打” shares the same structure with “风驰电掣” ). The subject should then recall the priming idiom and use one idiom to express the sentence's meaning (the target idiom's meaning) presented in front of himself. The result discovered that as to the consolidated Chinese idioms, there was a conspicuously grammatical structure priming effect in the speech production. Furthermore, no matter whether the target idioms' morpheme structures and the priming idioms' were same or not, as long as their structures were identical (e.g. both “风驰电掣” and “鸡飞蛋打” are in the type of the coordinative structure), the structure's priming effect would occur.

Nevertheless, working memory capacity of the subjects will have a comparatively large effect on the instantaneous sentence-recall paradigm. Therefore, this paradigm might be perfect for studying the syntactic priming effect in the simple sentence production or the phrase production (Chen, 2012).

\subsection{The Sentence Completion Paradigm}

Pickering \& Branigan (1998) initially used the written sentence completion paradigm to do researches on functions of the content word repetition in syntactic priming. Researchers first presented several incomplete sentences to the subjects (e.g. The racing driver showed the torn overall. (a prepositonal-object priming sentence)), and the priming sentence fragments are constrained by the syntax rules so as to be completed by either the prepositional-object or the double-object structures. After the completion of the priming sentence, the subject was 
presented the target sentence fragment which only has a subject and a verb (e.g. the patient showed), and he could arbitrarily choose one of the two structures to complete the target sentence. The result showed that sentences in the same structure were able to cause priming effect. In the meantime, the verb repetition between the priming sentence and the target sentence could enlarge the syntactic priming effect without the influence from the verb's tense, aspect and number, etc. This sentence completion paradigm also has found the syntactic priming effect in the oral completion task (Hartsuiker \& Westenberg, 2000).

There are some other paradigms for studying the speech production as well. Feng (2008) explored the foreign students' Chinese sentence production process by means of making sentences with words and using keywords to make sentences. Zhang \& Wang (2012) studied the intermediate level learners' syntactic priming effects under three circumstances—-sentence, phrase and word—via the method of reading sentences (even phrases or words).

The researches above mainly take the response biases of the target sentences produced by the subjects as the study index, and few experiments consider the reaction time (RT for short) as the measurement (except Corley \& Scheepers, 2002; Smith \& Wheeldon, 2001; Wheeldon, Smith \& Apperly, 2011; Wheeldon \& Smith, 2003). Because the pause during the sentence production needs to be controlled. The native speaker's pause in sentence can be controlled better than the non-native speaker's, and the pause seems inevitable during the non-native speaker's syntactic processing, so this situation should be meshed with good instructions.

Segaert, Menenti, Weber \& Hagoort (2011) studied the active sentences' and passive sentences' reaction times and response biases in the picture depiction task. In the Experiment One, the passive sentences' reaction quantity and the active sentences' reaction time had the priming effect. But when the passive sentences' production quantity was enhanced after the training in the Experiment Two, both these two types of sentences' quantity and reaction time could cause the priming effect as conducted in the procedures of Experiment One.

The reaction time adopted by the syntactic priming can be combined with ERP and fMRI. so as to inspect the activated cortex regions in the speech production. Menenti, Segaert \& Hagoort (2012) studied the activated cortex regions in the process of speech production by repeating the verbs, arguments or the structures. The result showed that the left cerebral hemisphere (esp. the left posterior middle temporal gyrus and the left inferior frontal gyrus) tended to process the syntactic information, the left temporal lobe stored the syntactic information related to lexicon, and the right cerebral hemisphere was inclined to manage the semantic information. Processing the syntax had its own functional independent cortex region which existed in a larger brain network.

\section{The Main Questions Studied by the Syntactic Priming}

\subsection{Is the Syntax Represented by the Abstract Syntactic Structure or the Construction}

The abstract syntactic structure denotes to the hierarchical word combination, and it is also called the hierarchical constituent structure. A sentence's syntactic knowledge can be defined by the phrase structure rules independent of words (Jackendoff, 1972). The phrase structure rules can rewrite the phrase as the rules analyzing the abstract structures, which have nothing to do with the specific words. For example, both “学生在食堂吃饭 (xuesheng-zai-shitang-chifan, students-in-the dining hall-eat, the students eat in the dining hall)” and “政府给百 姓服务” share the same abstract syntactic structure "NP + PP + VP", and the hierarchy can be expressed as “[NP + [PP + VP]]”.

Some researchers thought that as soon as the abstract syntactic structures divided by the phrase structure rules were identical, the priming would happen, no matter whether the function words or the content words were same or not (Bock, 1986, 1989), and that the syntactic priming had no relationship with the thematic roles (for instance, both the passive sentence "the 747 was alerted by the airport's control tower" and the progressive sentence "the 747 was landing by the airport's control tower" could improve the production of the passive sentences) (Bock \& Loebell, 1990). The phrase structure rules do not involve the empty category, so the sentence production does not touch upon the process of the syntactic transformation (Bock, Loebell, \& Morey, 1992). There are few Chinese studies being concerned about the abstract syntactic structure's priming which Zhang (2012) studied in the Chinese four-character idiom production.

The Construction is the combination of the form (the surface word categories or the word functions-subject, predicate, etc.) and the function/meaning (e.g. thematic role) (Goldberg, 1995, 2006). Some researchers deemed that the syntactic priming only happened at the construction level where the linear word categories' combination is coupled with the the thematic roles. For example, “学生在食堂吃饭” and “政府给百姓服务” share the same abstract syntactic structure, but “食堂 (dining hall)” expresses the location, “百姓 (people)” indicates the 
participant, so they are two different constructions. Hare \& Goldberg (1999) studied the representation of the syntactic priming: was it the syntactic tree structure which shows the pure syntactic knowledge or the certain match between form and meaning? Chang, Bock \& Goldberg (2003) also explored the thematic role’s function in the "spray-load" construction. Chinese researchers mainly focus on whether the construction causes priming or not during the sentence production, and the mutual relationship between meaning and syntax in the process of the production (Jiang, 2009; Zhang \& Lu, 2012; Xu \& Gao, 2013).

The discussion that the syntax is represented by the abstract syntactic structure or the construction is quite significant to the language teaching. If the syntactic knowledge could be stored and extracted by abstract syntactic structures, then the language teaching would have no need to distinguish the syntactic structures which are same in form but different in meaning. If the syntactic syntactic knowledge were stored and extracted by constructions, this would not only prove the psychological reality of the construction, but also provide differentiating the constructions with experimental methods, and teachers might organize their teaching activities in the light of the distinction of the homonymous constructions.

\subsection{The Psychological Reality of the Syntactic Hierarchical and the Linear Structure Representation}

Bock \& Levelt (1994) claimed that the syntactic processing during the speech production had two levels-the functional assignment level and the positional processing level. Words could obtain the syntactic functions in the functional assignment level and construct the hierarchical and linear structures in the level of positional processing. The current researches showed that both the hierarchical syntactic structure and the linear syntactic structure had the psychological reality.

Some researchers considered the result of the syntactic priming as a hierarchical structure. In the experiment of Bock \& Loebell (1990), the priming sentences included the prepositonal-object dative sentences (e.g. Susan brought a book to Stella), the infinitive sentences (e.g. Susan brought a book to study) and the double-object sentences (e.g. Susan brought the student a book), and the target pictures depicting the dative events. They discovered that only if the priming sentence was the prepositional-object dative one could the prepositonal-object sentence be produced, and the infinitive sentence which has the same sequence of the word categories (NP + VP + PP) could not facilitate the production of the prepositional-object sentence. Scheepers (2003) studied the German relative clause NP-of-NP-RC (e.g. the servant of the actress who)'s hierarchical priming. The result showed that due to the difference of the priming sentences' internal syntactic hierarchies, although the priming sentences share the same linear sequence of the word categories, they might have different priming effects. All the researches above have illustrated that the hierarchical syntactic structure representation had been activated.

Meanwhile, some studies found that the linear word sequence also had important influence upon the priming. Hartsuiker \& Westenberg (2000) studied the priming effect of the interchangeable past particles and the auxiliaries at the end of the clause in Dutch. For instance, De man belde de politie omdat zijn portemonnee was gestolen (The man called the police, because his wallet was stolen) and De man belde de politie omdat zijn portemonnee gestolen was (The man called the police, because his wallet stolen was) are both grammatical in Dutch. The result revealed that subjects tended to apply the priming sentences' word sequences into the target sentence completion, in which the word sequence priming occurred.

The researches of bilingualism pay more attention to the word sequence's impact on the cross-linguistic syntactic priming. Some researches (Bernolet, Hartsuiker, \& Pickering, 2007; Loebell \& Bock, 2003) found that in the process of the cross-linguistic syntactic priming, the word sequence could be activated, while other researches (Chen, Jia, Wang, Dunlap, \& Shin, 2013; Shin \& Christianson, 2009; Zhang \& Wang, 2012) argued that the word sequence could not be activated.

Thus, questions like whether the structure's hierarchy can be caused to prime in the cross-linguistic syntactic priming or not, and what the syntactic hierarchy's and the word sequence's functions are in the language production are worth to get studied further.

\subsection{Functions of the Word Repetition in the Sentence Production}

Pickering \& Branigan (1998) first discovered that the verb repetition between the priming sentence and the target sentence could improve the syntactic priming. Gries (2005) counted 3003 pairs of prepositonal-object and double-object sentences, and found that the structural priming happened in 2/3 of pairs, and that when the verbs 
were identical, the priming effect would magnify. The nouns' repetition in the complex noun phrases could also promote the syntactic priming (Cleland \& Pickering, 2003). And this phenomenon is called the lexical boost.

The function words act differently from the content words in the syntactic priming. For example, the preposition (such as to or for) repetition could not enhance the syntactic priming (Bock, 1989), and the different morphological forms of the verb (like showed and shows/showed and was showing) would not impact the syntactic priming effect either (Pickering \& Branigan, 1998).

The word repetition factor is also one of the focuses in the studies of the cross-linguistic syntactic priming. By studying the bilinguals, Schoonbaert et al. (2007) found that the word repetition in a single language (such as "give" in the priming sentence and the target sentence respectively in English) could result in larger syntactic priming effect than the word repetition between two different languages (like "gaven" in Dutch and "give" in English), whereas when there was no relationship between the priming sentence's verb and the target sentence's, the priming effects inside a language or among the languages would have no distinction. Through the study of Chinese as a second language production, Cao \& Mou (2013) discovered that the same patient nouns in both "BA" sentence and "BEI" sentence might have no significant impact upon the syntactic priming effect, but the same verbs could enhance the effect notably. The authors pointed out that during the production of Chinese as a second language, the verb lemma nodes could be activated greater than the noun lemma. On the contrary, Bernolet et al. (2007) did research on the syntactic priming of the complex noun phrases (Cleland \& Pickering, 2003) in the bilingual field (as in Dutch-English and Dutch-German), claiming that both the syntactic priming and lexical boost effects only happened in a single language, which could not exist between two languages. Hence, how to evaluate the content word repetition's function in the bilingual syntactic priming still entails to be contemplated harder.

\section{The Syntactic Priming's Mechanisms}

The syntactic priming's mechanisms mainly include the implicit learning theory (Ferreira \& Bock, 2006) and the residual activation theory (Pickering \& Branigan, 1998).

The implicit learning mechanism indicates that the syntactic priming is the process of strengthening the syntactic representation link. When producing or comprehending a syntactic structure, the user has to know how to map the sentence meaning to the functions (which is the subject, and which is the object), and how to map the functions to the component sequence, and the syntactic priming can reinforce the mapping. There are four characteristics illustrating the point that the syntactic priming is implicit: (1) the priming has no relationship with the explicit memory (Bock, Loebell, \& Morey, 1992); (2) the anterograde amnesia patients who suffer from the middle of the temporal injury and whose explicit memory has been injured seriously can have the syntactic priming effect (Ferreira, Bock, Wilson, \& Cohen, 2005); (3) the syntactic priming has the inverse preference effect, which means that the low-frequency sentences can make larger priming effect (Hartsuiker \& Kolk, 1998), being correlative with the error-based implicit learning calculations; (4) Chang's series of large-scale computer simulation studies proved that the syntactic priming was implicit (Chang, 2002; Chang, Dell, \& Bock, 2006; Chang, Dell, Bock, \& Griffin, 2000). The researchers who believe in the implicit learning deemed that: (1) the syntactic priming's syntactic structure was composed of the abstract syntactic frame; (2) the priming was related to long term memory; (3) the concrete words were filled into the syntactic frame during the speech production; (4) the promoting function of the word repetition was in relation to the sentence meaning, which was a short time phenomenon.

According to language production model of Levelt, Roelofs \& Meyer (1999) and Roelofs (1992, 1993), Pickering \& Branigan (1998) proposed the single mechanism model of the syntactic priming and the lexical boost, also, i.e. the lexical residual activation theory. They claimed that the lemma level contained the verb's category nodes including the feature nodes like gender, number and case, etc., and the verb's syntactic combination's combinatorial nodes. When the verb was used in a specific structure, the combinatorial nodes would be activated. For instance, when "give" is used in the prepositional-object structure, the combinatorial nodes- NP and PPwould be activated; when "give" is used in the double-object structure, the nodes—NP and NP—would be activated instead. When the speaker produces "John gave a book to the boy", the lemma, GIVE, the combinatorial nodes, NP and PP, and their relationship will be activated. These nodes and the relationship's activated state will recede but not disappear immediately, therefore, the target sentence's syntactic structure's priming can be realized. On the basis of Pickering \& Branigan (1998), Hartsuiker, Pickering \& Veltkamp (2004) put forward the 
bilingual verb syntactic representation model emphasizing that the internal mechanism of the cross-linguistic structural priming was the activation of the cross-linguistic syntactic representation of lemma.

By comparing the two viewpoints above, we found that the researchers who insist on that the syntactic priming belongs to the implicit learning think that the sentence production is impacted largely by the syntactic frame, and the lexical and syntactic knowledge are mutually independent; that the researchers who hold the idea that the syntactic priming pertains to the lexical residual activation deem that the lexical activation is the motive for the syntactic priming, and that the sentence production is driven by the lexicon. This kind of controversy has a close bearing on the "verb center hypothesis", the "construction view" and the "the syntactic representation of verb”, etc.

\section{Summary and Outlook}

As an important research method for studying the syntactic representation, the syntactic priming is receiving more and more attention from the linguists, psychologists and the neuropsychologists. The researchers have explored a series of questions in this field, for example:

(1) What is caused to prime? The abstract syntactic structure or the construction?

(2) What is to represent the syntax? The hierarchical syntactic structure or the linear one?

(3) What can cause the syntactic priming? The thematic role, event structure (Bunger, Papafragou, \& Trueswell, 2013) or the word repetition?

(4) What is the mechanism behind the syntactic priming?

(5) What is the function of the syntactic frame and the words during the speech production?

Most studies above are based on the native speakers. By studying the questions mentioned above in the second language acquisition may be very conducive to revealing the second language production's internal mechanism, and combing the research results to the second language teacher's classroom language and second language textbook compilation so as to improve teaching efficiency.

Meanwhile, as a experimental paradigm, the syntactic priming is strict with the target sentences' interchangeability, so that the prepositional/double-object dative sentences and the active/passive sentences are preferred materials for the priming experiments. However, the semantic difference of the active sentence and the passive sentence in Chinese urges researchers to consider other interchangeable sentence patterns to explore the syntactic priming.

Finally, recent researches hardly adopt the reaction time as an index to study the syntactic priming during the speech production. Therefore, future researches may combine the reaction time with ERP, fMRI, etc., to inspect the cortex regions activated by the syntax during the speech production so as to answer the question about what the brain's processing mechanism is in the stage of the sentence production with more specific data.

\section{References}

Bernolet, S., Hartsuiker, R. J., \& Pickering, M. J. (2007). Shared Syntactic Representations in Bilinguals: Evidence for the Role of Word-Order Repetition. Journal of Experimental Psychology: Learning, Memory, and Cognition, 33, 931-949. http://dx.doi.org/10.1037/0278-7393.33.5.931

Bock, J. K. (1986). Syntactic Persistence in Language Production. Cognitive Psychology, 18, 355-387. http://dx.doi.org/10.1016/0010-0285(86)90004-6

Bock, K. (1989). Closed-Class Immanence in Sentence Production. Cognition, 31, 163-186. http://dx.doi.org/10.1016/0010-0277(89)90022-X

Bock, K., \& Levelt, W. J. M. (1994). Language Production: Grammatical Encoding. In M. A. Gernsbacher (Ed.), Handbook of Psycholinguistics (pp. 945-984). San Diego, CA: Academic Press.

Bock, K., \& Loebell, H. (1990). Framing Sentences. Cognition, 35, 1-39. http://dx.doi.org/10.1016/0010-0277(90)90035-I

Bock, K., Dell, G. S., Chang, F., \& Onishi, K. H. (2007). Persistent Structural Priming from Language Comprehension to Language Production. Cognition, 104, 437-458. http://dx.doi.org/10.1016/j.cognition.2006.07.003

Bock, K., Loebell, H., \& Morey, R. (1992). From Conceptual Roles to Structural Relations: Bridging the Syntactic Cleft. Psychological Review, 99, 150-171. http://dx.doi.org/10.1037/0033-295X.99.1.150

Branigan, H. P., Pickering, M. J., \& Cleland, A. A. (2000). Syntactic Co-Ordination in Dialogue. Cognition, 75, B13-B25. http://dx.doi.org/10.1016/S0010-0277(99)00081-5

Bunger, A., Papafragou, A., \& Trueswell, C. J. (2013). Event Structure Influences Language Production: Evidence from 
Structural Priming in Motion Event Description. Journal of Memory and Language, 69, 299-323. http://dx.doi.org/10.1016/j.jml.2013.04.002

Cao, X.-W., \& Mu, L. (2013). Syntactic Priming in Chinese L2 Speakers’ Production. Chinese Language Learning, 4 , 80-86.

Chang, F. (2002). Symbolically Speaking: A Connectionist Model of Sentence Production. Cognitive Science, $26,609-651$. http://dx.doi.org/10.1207/s15516709_og2605_3

Chang, F., Bock, J. K., \& Goldberg, A. (2003). Can Thematic Roles Leave Traces of Their Places? Cognition, 90, $29-49$. http://dx.doi.org/10.1016/S0010-0277(03)00123-9

Chang, F., Dell, G. S., \& Bock, K. (2006). Becoming Syntactic. Psychological Review, 113, 234-272. http://dx.doi.org/10.1037/0033-295X.113.2.234

Chang, F., Dell, G. S., Bock, J. K., \& Griffin, Z. M. (2000). Structural Priming as Implicit Learning: A Comparison of Models of Sentence Production. Journal of Psycholinguistic Research, 29, 217-229. http://dx.doi.org/10.1023/A:1005101313330

Chen, Q.-R. (2012). Syntactic Priming: Paradigm and Controversy in Language Comprehension. Advances in Psychological Science, 20, 208-218.

Chen, B., Jia, Y., Wang, Z., Dunlap, S., \& Shin, J.-A. (2013). Is Word-Order Similarity Necessary for Cross-Linguistic Structural Priming? Second Language Research, 29, 375-389. http://dx.doi.org/10.1177/0267658313491962

Cleland, A. A., \& Pickering, M. J. (2003). The Use of Lexical and Syntactic Information in Language Production: Evidence from the Priming of Noun-Phrase Structure. Journal of Memory and Language, 49, 214-230. http://dx.doi.org/10.1016/S0749-596X(03)00060-3

Cleland, A. A., \& Pickering, M. J. (2006). Do Writing and Speaking Employ the Same Syntactic Representations? Journal of Memory and Language, 54, 185-198. http://dx.doi.org/10.1016/j.jml.2005.10.003

Corley, M., \& Scheepers, C. (2002). Syntactic Priming in English Sentence Production: Categorical and Latency Evidence from an Internet-Based Study. Psychonomic Bulletin \& Review, 9, 126-131. http://dx.doi.org/10.3758/BF03196267

Feng, L.-P. (2008). A Study of Structural Transfer Effect in the Process of Chinese Sentence Production. Journal of Yunnan Normal University, 6, 25-31.

Ferreira, V. S. (2003). The Persistence of Optional Complementizer Production: Why Saying “That” Is Not Saying “That” at All. Journal of Memory and Language, 48, 379-398. http://dx.doi.org/10.1016/S0749-596X(02)00523-5

Ferreira, V. S., \& Bock, J. K. (2006). The Functions of Structural Priming. Language and Cognitive Processes, 21, 10111029. http://dx.doi.org/10.1080/01690960600824609

Ferreira, V. S., Bock, J. K., Wilson, M., \& Cohen, N. J. (2005). Structural Persistence in Anterograde Amnesia: Evidence for Implicit Learning. Paper Presented at the 46th Annual Meeting of the Psychonomic Society, Toronto, 11-13 October 2005, 45.

Goldberg, A. E. (1995). Constructions: A Construction Grammar Approach to Argument Structure. Chicago, IL: University of Chicago Press.

Goldberg, A. E. (2006). Constructions at Works: The Nature of Generalization in Language. New York: Oxford University Press.

Gries, S. T., \& Wulff, S. (2005). Do Foreign Language Learners Also Have Constructions? Evidence from Priming, Sorting, and Corpora. Annual Review of Cognitive Linguistics, 3, 182-200. http://dx.doi.org/10.1075/arcl.3.10gri

Hare, M. L., \& Goldberg, A. E. (1999). Structural Priming: Purely Syntactic? In M. Hahn, \& S. C. Stones (Eds.), Proceedings of the 21st Annual Meeting of the Cognitive Science Society (pp. 208-211). Mahwah, NJ: Erlbaum.

Hartsuiker, R. J., \& Kolk, H. H. J. (1998). Syntactic Persistence in Dutch. Language and Speech, 41, 143-184.

Hartsuiker, R. J., \& Westenberg, C. (2000). Word Order Priming in Written and Spoken Sentence Production. Cognition, 75, B27-B39. http://dx.doi.org/10.1016/S0010-0277(99)00080-3

Hartsuiker, R. J., Kolk, H. H. J., \& Huiskamp, P. (1999). Priming Word Order in Sentence Production. Quarterly Journal of Experimental Psychology, 52, 129-147. http://dx.doi.org/10.1080/713755798

Hartsuiker, R. J., Pickering, M. J., \& Veltkamp, E. (2004). Is Syntax Separate or Shared between Languages? Cross-Linguistic Syntactic Priming in Spanish-English Bilinguals. Psychological Science, 15, 409-414. http://dx.doi.org/10.1111/j.0956-7976.2004.00693.x

Jackendoff, R. S. (1972). Semantic Interpretation in Generative Grammar. Cambridge, MA: MIT Press.

Jiang, L. (2009). The Cross-Language Structural Priming of Passive Constructions and Its Mechanism. Modern Foreign Languages, 35, 54-61. 
Levelt, W. J. M., Roelofs, A., \& Meyer, A. S. (1999). A Theory of Lexical Access in Speech Production. Behavioral and Brain Sciences, 22, 1-75. http://dx.doi.org/10.1017/S0140525X99001776

Loebell, H., \& Bock, K. (2003). Structural Priming across Languages. Linguistics, 41, 791-824. http://dx.doi.org/10.1515/ling.2003.026

McDonough, K. (2006). Interaction and Syntactic Priming: English L2 Speakers’ Production of Dative Constructions. Studies in Second Language Acquisition, 28, 179-207. http://dx.doi.org/10.1017/S0272263106060098

Menenti, L., Segaert, K., \& Hagoort, P. (2012). The Neuronal Infrastructure of Speaking. Brain \& Language, $122,71-80$. http://dx.doi.org/10.1016/j.bandl.2012.04.012

Pickering, M. J., \& Branigan, H. P. (1998). The Representation of Verbs: Evidence from Syntactic Priming in Language Production. Journal of Memory and Language, 39, 633-651. http://dx.doi.org/10.1006/jmla.1998.2592

Pickering, M. J., \& Ferreira, V. S. (2008). Structural Priming: A Critical Review. Psychological Bulletin, 134, 427-459. http://dx.doi.org/10.1037/0033-2909.134.3.427

Potter, M. C., \& Lombardi, L. (1998). Syntactic Priming in Immediate Recall of Sentences. Journal of Memory and Language, 38, 265-282. http://dx.doi.org/10.1006/jmla.1997.2546

Roelofs, A. (1992). A Spreading-Activation Theory of Lemma Retrieval in Speaking. Cognition, 42, 107-142. http://dx.doi.org/10.1016/0010-0277(92)90041-F

Roelofs, A. (1993). Testing a Non-Decompositional Theory of Lemma Retrieval in Speaking: Retrieval of Verbs. Cognition, 47, 59-87. http://dx.doi.org/10.1016/0010-0277(93)90062-Z

Scheepers, C. (2003). Syntactic Priming of Relative Clause Attachments: Persistence of Structural Configuration in Sentence Production. Cognition, 89, 179-205. http://dx.doi.org/10.1016/S0010-0277(03)00119-7

Schoonbaert, S., Hartsuiker, R. J., \& Pickering, M. J. (2007). The Representation of Lexical and Syntactic Information in Bilinguals: Evidence from Syntactic Priming. Journal of Memory and Language, 56, 153-171. http://dx.doi.org/10.1016/j.jml.2006.10.002

Segaert, K., Menenti, L., Weber, K., \& Hagoort, P. (2011). A Paradox of Syntactic Priming: Why Response Tendencies Show Priming for Passives and Response Latencies Show Priming for Actives. PLoS ONE, 6, e24209. http://dx.doi.org/10.1371/journal.pone.0024209

Shin, J.-A., \& Christianson, K. (2009). Syntactic Processing in Korean-English Bilingual Production: Evidence from CrossLinguistic Syntactic Priming. Cognition, 112, 175-180. http://dx.doi.org/10.1016/j.cognition.2009.03.011

Smith, M., \& Wheeldon, L. (2001). Syntactic Priming in Spoken Sentence Production: An Online Study. Cognition, 78, $123-$ 164. http://dx.doi.org/10.1016/S0010-0277(00)00110-4

Weiner, E. J., \& Labov,W. (1983) Constraints on the Agentless Passive. Journal of Linguistics, 19, 29-58. http://dx.doi.org/10.1017/S0022226700007441

Wheeldon, L. R., \& Smith, M. C. (2003). Phrase Structure Priming: A Short Lived Effect. Language and Cognitive Processes, 18, 431-442. http://dx.doi.org/10.1080/01690960244000063

Wheeldon, L. R., Smith, M. C., \& Apperly, I. A. (2011). Repeating Words in Sentences: Effects of Sentence Structure. Journal of Experimental Psychology: Learning, Memory, and Cognition, 37, 1051-1064. http://dx.doi.org/10.1037/a0023435

Yang, Z., \& Shi, C. H. (2013). Acquisition of Chinese Quasi-Divalent Verbs and Its Built-In Mechanism in CSL. Chinese Teaching in the World, 27, 558-573.

Zha, Y. Y. \& Wu, S. N. (2014). Syntactic Priming in L1 and L2 Chinese. Language Teaching and Linguistic Studies, 35, 1319.

Zhang, J. J., \& Lu, S. M. (2012). Syntactic Priming Effect in Language Production of Chinese-English Bilinguals. Journal of Xi'an International Studies University, 20, 5-8.

Zhang, J. Q., \& Wang, M. Y. (2012). On Syntactic Priming Effect in Intermediate Overseas Students' Sentence Production. TCSOL Studies, 50, 51-56.

Zhang, J. Q., \& Wang, Y. (2012). Cross Language Syntactic Priming of Overseas Indonesian Students in the Production of Chinese Sentences. Studies of Psychology and Behavior, 10, 297-300.

Zhang, J. Q. (2012). The Priming Effect of the Grammatical Structure in the Production of Chinese Idioms. Journal of Psychological Science, 35, 852-856. 
Scientific Research Publishing (SCIRP) is one of the largest Open Access journal publishers. It is currently publishing more than 200 open access, online, peer-reviewed journals covering a wide range of academic disciplines. SCIRP serves the worldwide academic communities and contributes to the progress and application of science with its publication.

Other selected journals from SCIRP are listed as below. Submit your manuscript to us via either submit@scirp.org or Online Submission Portal.
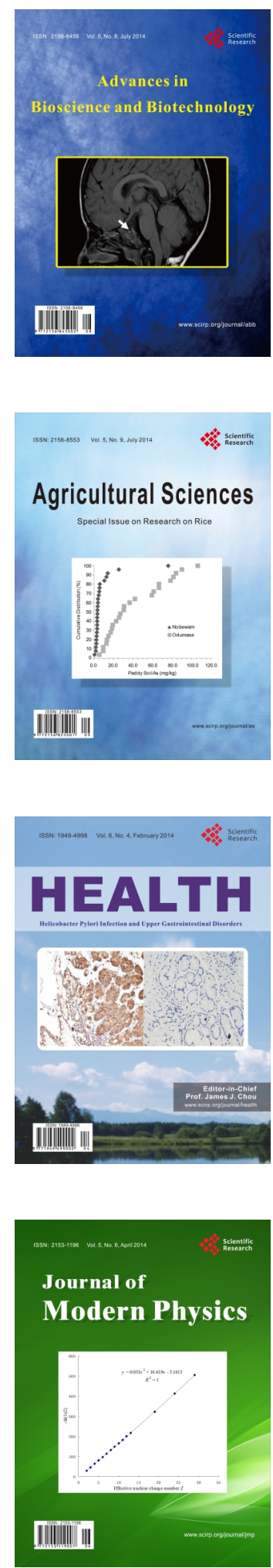
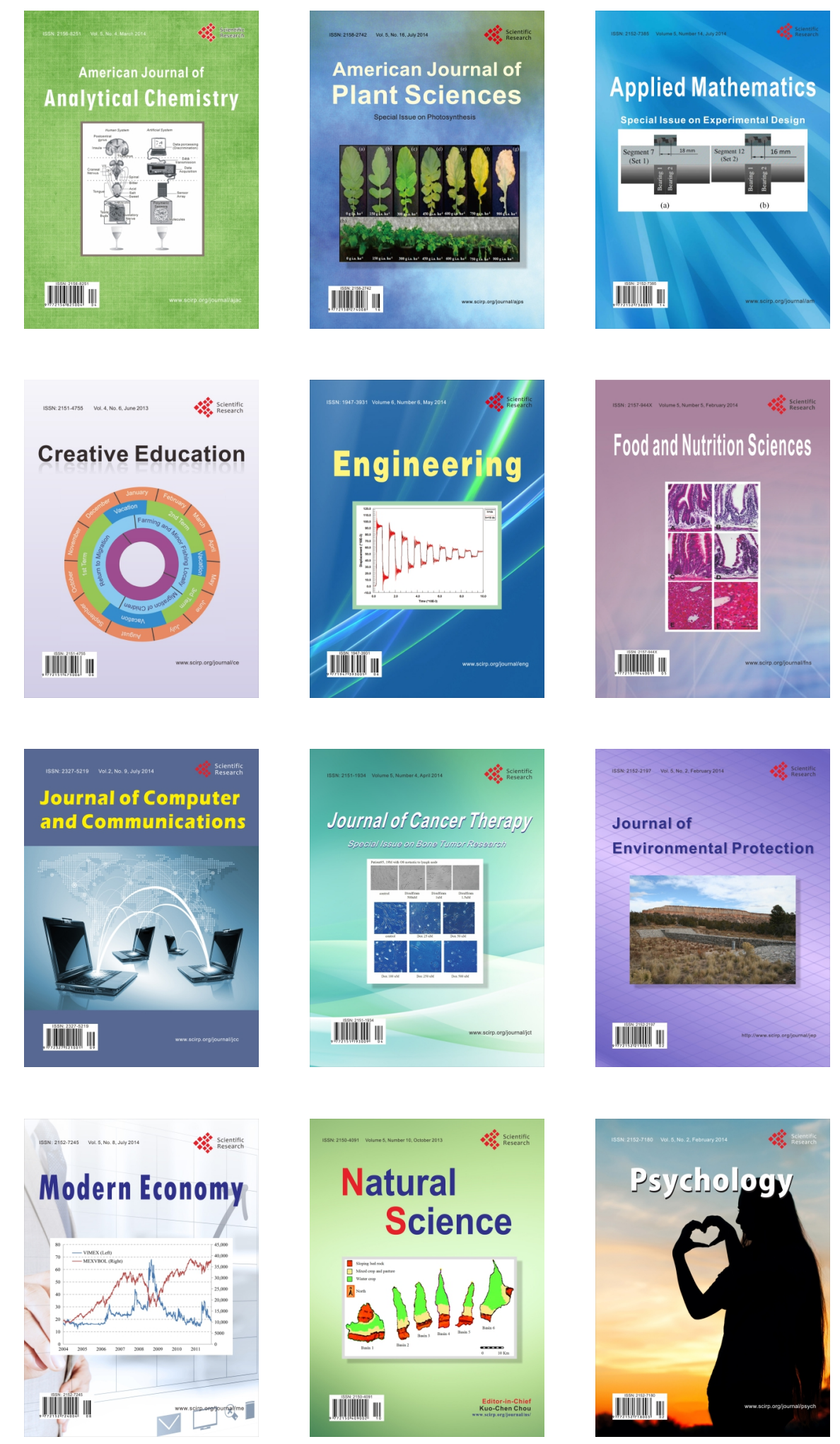